\title{
Perubahan Makna Perayaan Maulid Nabi Muhammad SAW bagi Masyarakat Kelurahan Dasan Agung Kecamatan Selaparang Kota Mataram
}

\author{
Khaerunnisa, Ika Wijayanti, Siti Nurjannah \\ Universitas Mataram
}

\begin{abstract}
The Prophet's Maulid celebration is one of the celebrations of Muslims day. Almost all over Lombok always commemorates the celebration of the Prophet's Maulid with joy. One of the areas in Mataram city that has uniqueness on the celebration of the Prophet's Maulid is Kelurahan Dasan Agung, the community has a unique ritual in the celebration of the Prophet Maulid because of the procession and celebrations that are packed such as parties equipped with Music. This uniqueness is a form of cultural change in the celebration of the Maulid of the Prophet Muhammad. The research methods used are qualitative research. This is because the research aims to understand the linkages caused by the change of meaning and social change of culture that occurred in the celebration of the Prophet Maulid. The data required in this study are primary data such as interviews and documentation results, as well as secondary data such as Kelurahan profiles, citizen documentation, and community Journal Records. Data collection techniques in four ways are field and data observation, document tracing, interviews, and documentation. The Prophet's Maulid celebration for the people of Dasan Agung still has the same usage of the Prophet's Maulid celebration in general. However, on some series of celebrations of the Prophet's Mawlid in Kelurahan Dasan Agung have changed. One of the series of celebrations of the Prophet Muhammad SAW that is quite a lot of change is in Praje. Praje is one of the series of the Mawlid celebration of the Prophet Muhammad SAW in the village of Dasan Agung who has existed since the first time. The music accompanying the Praje also underwent a change in the early 80 's from religious music to Dangdut music, until now using a variety of music.
\end{abstract}

Keywords: Prophet's Maulid celebration, social culture change, meaning change

\begin{abstract}
Abstrak
Perayaan Maulid Nabi merupakan salah satu perayaan hari besar umat Islam. Hampir di seluruh penjuru Lombok selalu memperingati perayaan Maulid Nabi dengan suka cita. Salah satu daerah di Kota Mataram yang memiliki keunikan pada perayaan MAulid Nabi ialah Kelurahan Dasan Agung, masyarakat memiliki ritual yang unik dalam perayaan Maulid Nabi karena adanya arak-arakan serta perayaan yang dikemas seperti pesta dilengkapi dengan musik-musik. Keunikan tersebut merupakan suatu bentuk adanya perubahan budaya pada perayaan Maulid Nabi Muhammad. Metode penelitian yang digunakan ialah penelitian kualitatif eksplanatif. Hal ini dikarenakan pada penelitian ini bertujuan untuk memahami keterkaitan sebab akibat adanya perubahan makna dan perubahan sosial budaya yang terjadi pada perayaan Maulid Nabi. Data yang diperlukan pada penelitian ini yaitu data primer seperti hasil wawancara dan dokumentasi, serta data sekunder seperti profil kelurahan, dokumentasi warga, dan catatan jurnal masyarakat. Teknik pengumpulan data menggunakan empat cara yaitu observasi lapangan dan data, penelusuran dokumen, wawancara, dan dokumentasi. perayaan Maulid Nabi bagi masyarakat Dasan Agung masih memiliki
\end{abstract}


pemaknaan yang sama mengenai perayaan Maulid Nabi secara umum. Namun, pada beberapa rangkaian perayaan maulid nabi di Kelurahan Dasan Agung mengalami perubahan. Salah satu rangkaian perayaan maulid nabi Muhammad SAW yang cukup banyak mengalami perubahan ialah pada praje. Praje merupakan salah satu rangkaian perayaan maulid nabi Muhammad SAW di kelurahan Dasan Agung yang sudah ada sejak dahulu. Musik yang mengiringi praje juga mengalami perubahan diawal tahun 80 -an dari musikmusik religius menjadi musik dangdut, hingga sekarang menggunakan berbagai macam musik.

Kata Kunci : Perayaan Maulid Nabi, Perubahan Sosial Budaya, Perubahan Makna

\section{Pendahuluan}

Masyarakat NTB khususnya yang berada di Pulau Lombok terkenal dengan kekentalan ilmu agama dalam kesehariannya dan mendapat julukan Pulau Seribu Masjid. Julukan itu pada dasarnya mengacu pada jumlah masjid yang sangat banyak di Lombok. Diketahui bahwa jumlah masjid yang ada di Lombok pada tahun 2016 yaitu 3.350 masjid (BPS NTB tahun 2017). Akan tetapi makna tersebut tidak hanya pada sebatas jumlah masjid saja, melainkan juga karena masyarakat Lombok dikenal sebagai masyarakat yang sangat mengedepankan nilai agama.

Perayaan Maulid Nabi merupakan salah satu perayaan hari besar umat Islam. Hampir di seluruh penjuru Lombok selalu memperingati perayaan Maulid Nabi dengan suka cita. Bahkan tidak jarang mengadakan lomba-lomba yang berbau keagamaan seperti, lomba adzan, lomba membaca terjemahan Al-Quran dan sebagainya. Salah satu daerah yang terkenal dengan perayaan maulidnya ialah daerah Lombok Tengah. Masyarakat Lombok Tengah sangat antusias menyambut Maulid Nabi, biasanya setiap rumah akan merayakan Maulid Nabi dengan mengadakan syukuran serta makan bersama dengan mengundang tetangga, kerabat dan teman. Selain itu, masyarakat Kota Mataram yang dekat dengan kehidupan perkotaan dan identik dengan memudarnya penerapan agama juga merayakan maulid dengan suka cita dan tidak berbeda jauh dengan perayaan yang ada di daerah lain di Lombok.

Salah satu daerah di Kota Mataram yang memiliki keunikan pada perayaan MAulid Nabi ialah Kelurahan Dasan Agung. Kelurahan Dasan Agung merupakan salah satu daerah dengan penduduk asli Kota Mataram dan masih memelihara kebudayaannya. Di Dasan Agung, masyarakat memiliki ritual yang unik dalam perayaan Maulid Nabi karena adanya arak-arakan serta perayaan yang dikemas seperti pesta dilengkapi dengan musik-musik. Keunikan tersebut merupakan suatu bentuk adanya perubahan budaya pada perayaan Maulid Nabi Muhammad. 


\section{Landasan Teoritis}

Salah satu penelitian terdahulu yang dijadikan referensi ialah Tradisi Maulid Nabi Dalam Masyarakat Sasak oleh Zaenuddin Mansyur, Ulumuna Volume IX Edisi 15 No. 1 Januari-Juni tahun 2005. Penelitian ini bertujuan untuk mengetahui praktek upacara perayaan maulid Nabi Muhammad SAW. pada masyarakat Suku Sasak. Adapun fokus pada penelitian ini ialah tentang bagaimana tradisi praktek maulid Nabi Muhammad SAW. dalam perspektif masyarakat Sasak Lombok dan mengapa upacara peryaan maulid Nabi Muhammad SAW. itu dirayakan dengan tradisi yang kental oleh masyarakat Sasak.

Sztompka merumuskan pengertian tradisi dalam arti sempit, tradisi adalah kumpulan benda material dan gagasan yang diberi makna khusus yang berasal dari masa lalu. Tradisi tidak hanya berupa kesenian yang biasa kita lihat sehari. Basis tradisi menurut Sztompka mencakup gagasan masa lalu yang saling berinteraksi dan ditularkan kepada generasi yang baru. Sztompka mengatakan bahwa terdapat dua cara pembentukan tradisi, yaitu cara pertama muncul dari bawah melalui mekanisme kemunculan secara spontan dan tak diharapkan serta melibatkan rakyat banyak. Cara kedua dari atas melalui mekanisme paksaan. Sesuatu yang dipaksakan oleh individu yang berpengaruh atau berkuasa. Tradisi pun mengalami perubahan. Tradisi lahir disaat tertentu di saat tertentu ketika orang menetapkan fragmen tertentu dari warisan masa lalu sebagai tradisi. Tradisi berubah ketika orang memberikan perhatian khusus pada fragmen tradisi tertentu dan mengabaikan fragmen yang lain. Tradisi bertahan dalam jangka waktu tertentu dan mungkin lenyap bila benda material dibuang dan gagasan ditolak atau dilupakan. Tradisi mungkin pula hidup dan muncul kembali setelah lama terpendam.

Selain itu, Sztompka juga mengatakan bahwa tradisi mengalami perubahan juga dipengaruhi oleh banyaknya tradisi dan bentrokan antara tradisi yang satu dengan lainnya. Interaksi yang terjadi antara dua budaya yang hidup berdampingan seringkali mengalami konflik, yang kemudian mampu menciptakan perubahan. Menurut Sztompka perubahan sosial dapat dibayangkan sebagai perubahan yang terjadi di dalam atau mencakup sistem sosial. Lebih tepatnya, terdapat perbedaan antara keadaan sistem tertentu dalam jangka waktu berlainan (Sztompka, 2014: 3). Perubahan sosial seringkali dimulai dengan adanya pertambahan jumlah penduduk, hal ini dikarenakan semakin meningkatnya kuantitas suatu masyarakat akan semakin meningkatkan gagasan-gagasan yang ada. Seperti yang telah diuraikan pada pembahasan sebelumnya dimana tradisi mengalami perubahan dikarenakan adanya persingungan antara dua kebudayaan.

Bagi Schutz tugas utama fenomenologi ialah menguhubungkan antara pengetahuan ilmiah dengan pengalaman sehari-hari (Kuswarno, 2013: 17). Setiap individu memiliki pengetahuan ilmiah atau stock of knowledge yang berbeda-beda yang mampu memengaruh pemaknaan. Menurut Schutz, tindakan sosial didasarkan 
pada pengalaman, makna, dan kesadaran. Dikatakan bahwa tindakan sosial didasarkan oleh pengalaman, makna, dan kesadaran. Hal ini dikarenakan, dalam kehidupan sehari-hari kita melihat berbagai kejadian baik yang pada diri kita ataupun pada orang lain yang kemudian bisa sebut sebagai pengalaman.

\section{Metode Penelitian}

Metode penelitian yang digunakan ialah penelitian kualitatif eksplanatif. Hal ini dikarenakan pada penelitian ini bertujuan untuk memahami keterkaitan sebab akibat adanya perubahan makna dan perubahan sosial budaya yang terjadi pada perayaan Maulid Nabi. Lokasi penelitian dilakukan di Kelurahan Dasan Agung dengan unit analisis yaitu individu di dalam masyarakat yaitu masyarakat yang teribat dalam proses perayaan maupun individu ytang tidak terlibat. Penentuan informan penelitian menggunakan teknik purposive sampling, yaitu dengan pertimbangan tertentu. Adapun informan pada penelitian ini yaitu remaja, pemuda, orang dewasa, serta tokoh masyarakat. Penentuan ini dirasa sesuai dengan unit analisis dan tujuan penelitian. Data yang diperlukan pada penelitian ini yaitu data primer seperti hasil wawancara dan dokumentasi, serta data sekunder seperti profil kelurahan, dokumentasi warga, dan catatan jurnal masyarakat.

Teknik pengumpulan data menggunakan empat cara yaitu 1) observasi lapangan dan data bertujuan untuk mencari informasi awal mengenai subjek penelitian. 2) penelusuran dokumen dilakukan untuk menunjang observasi awal, serta memberi informasi mengenai kondisi sosial geografis. 3) wawancara dilakukan untuk mendapatkan informasi dari para informan selaku subjek penelitian. 4) dokumentasi bertujuan sebagai rekam jejak penelitian serta memberi keabsahan data penelitian. Analisis data dilakukan dengan teknik analisis data Spradley, yaitu menemukan domain-domain dari data yang terkumpul baik dari wawancara mendalam maupun observasi lapangan atau analisis dokumen, kemudian setelah itu melakukan analisis teksonomi yang merupakan analisis tahap lanjutan dalam mencari atau merumuskan rincian dari domain-domain yang sudah didapatkan sebelumnya. Penelitian ini dilakukan pada bulan Oktober 2018.

\section{Hasil dan Pembahasan}

Kelurahan Dasan Agung, Kecamatan Selaparang merupakan salah satu dari 50 (lima puluh) Kelurahan yang ada di Kota Mataram, yang berjarak dari $\pm 1 \mathrm{Km}$ dari pusat pemerintahan Kota Mataram. Awal mula terbentuknya Kelurahan Dasan Agung pada Tahun 1980 yang terdiri 15 lingkungan dengan keragaman etnis dan suku. Pada Tahun 2007 terjadi pemekaran kecamatan dan Kelurahan berdasarkan Perda Kota Mataram Nomor 3 Tahun 2007 yang membagi Kelurahan Dasan Agung menjadi 2 (dua) kelurahan. Seiring berjalannya waktu dan pertimbangan kepadatan 
penduduk pada salah satu Wilayah Lingkungan maka pada tahun 2010 kembali terjadi pemekaran Lingkungan yang awalnya 12 lingkungan menjadi 13 lingkungan sampai dengan sekarang. Kelurahan Dasan Agung terdiri dari 13 lingkungan yang dijabat oleh Kepala Lembaga Kemasyarakatan sebagai perpanjangan tangan Lurah. Adapun jumlah RT (Rukun Tetangga) yang ada di Kelurahan Dasan Agung sejumlah 48 RT.

Luas wilayah Kelurahan Dasan Agung seluas \pm 97 Ha dengan letak geografis sebagai berikut. Sebelah Utara berbatasan dengan Kelurahan Kebun Sari, sebelah Timur berbatasan dengan Kelurahan Monjok Barat. Sebelah Selatan berbatasan dengan Kelurahan Gomong, dan sebelah Barat berbatasan dengan Kelurahan Dasan Agung Baru. Kelurahan Dasan Agung berada $\pm 5 \mathrm{~m}$ di atas permukaan laut dengan curah hujan ratarata $3.000-4.000 \mathrm{~mm} / \mathrm{tahun}$ dan suhu udara rata-rata $30^{\circ}$ C. Penduduk di Kelurahan Dasan Agung berjumlah 8.349 jiwa terdiri atas penduduk laki-laki 3.980 jiwa dan penduduk perempuan 4.369 jiwa. Berikut jumlah penduduk berdasarkan lingkungan di Kelurahan Dasan Agung.

Dalam proses perayaan Maulid Nabi Muhammad SAW terdapat dua rangkaian yang dilakukan yaitu persiapan perayaan dan pelaksaan perayaan. Adapun tahap persiapan dilakukan untuk meyokong keperluan yakni (1) Rapat persiapan rapat, sebelum menyelenggarakan perayaan maulid nabi masyarakat Dasan Agung melakukan musyawarah mengenai panitia yang bertugas selama rangkaian perayaan maulid. Masyarakat yang terlibat sebagai panitia ialah tokoh masyarakat dan dibantu oleh para pemuda dan masyarakat. (2) Persiapan lomba, perlombaan biasanya dilakukan sebelum perayaan maulid nabi sebagai salah satu rangkaian untuk menyambut hari maulid. Pada masyarakat Dasan Agung, sebelum mengadakan lomba terlebih dahulu remaja mempersiapkan perlengkapan serta seluruh persiapan terkait lomba yang diadakan. (3) Menghias jalan dan masjid, untuk memeriahkan perayaan Maulid Nabi masyarakat Dasan Agung biasanya memberikan hiasan pada jalan-jalan dan masjid berupa umbul-umbul dan janur. (4) Penampahan, yaitu kegiatan memasak yang biasanya dilakukan oleh ibu-ibu sebagai persiapan untuk dulang, dilakukan satu hari sebelum perayaan Maulid Nabi. (5) Persiapan tamu undangan, masyarakat Dasan Agung mengundang seorang ustadz atau kiyai sebagai penceramah yang memberikan tausiyah kepada tamu undangan. Tamu undangan ialah para pemuka-pemuka agama serta tokoh-tokoh di setiap lingkungan Dasan Agung. Adapun yang harus dipersiapkan yaitu surat undangan untuk satiap tamu undangan. (6) Persiapan praje, Praje adalah tradisi masyarakat Sasak mengarak anak-anak yang sudah dikhitan menggunakan kuda-kudaan diiringi dengan musik-musik tradisional. Biasanya diarak mengelilingi daerah sekitar lingkungan tempat tinggal. Praje atau arak-arakan sebagai salah satu rangkaian perayaan Maulid Nabi di Dasan Agung membutuhkan beberapa persiapan baik perlengkapan maupun kesiapan ekonomi untuk keperluan lainnya seperti makan dan 
minum tamu undangan. Dikarenakan biaya yang diperlukan untuk mengadakan praje cukup besar berkisar lima juta yaitu untuk menyewa praje atau kuda-kudaan, sound system, mobil pick up, makanan dan minuman untuk menjamu para tamu undangan maka masyarakat Dasan Agung memiliki kebiasaan menabung sepanjang tahun untuk memenuhi keperluan tersebut.

Rangkaian proses perayaan maulid Nabi Muhammad SAW dimulai sejak satu minggu sebelum perayaan maulid. Dimulai dengan lomba-lomba seperti lomba adzan, lomba tilawah serta lomba-lomba berbau agama. Kemudian dilanjutkan dengan perayaan maulid nabi di masjid diisi oleh ceramah yang dibawakan oleh ustadz atau kiyai. Setelah itu pada malamnya ada perayaan praje yang dikhususkan untuk memberikan ucapan selamat kepada anak-anak yang telah dikhitan. Kemudian dilanjutkan dengan pawai selama tiga hari berturut-turut dibarengi dengan adanya shalawat untuk masjid. (1) Pelaksanaan lomba, pada masyarakat Dasan Agung terdapat dua waktu pelaksanaan lomba yaitu sebelum perayaan dan sesudah perayaan maulid nabi. Lomba yang dilakukan sebelum perayaan ialah lomba-lomba yang berbau keagamaan seperti lomba adzan, lomba membaca atau menghafal surat pendek, lomba busana muslim, lomba pidato, serta lomba tilawah. Pelaksanaan lomba tersebut ialah satu minggu sebelum pelaksanaan perayaan maulid nabi. (2) Pelaksanaan perayaan Maulid Nabi di masjid, Perayaan inti maulid nabi di Dasan Agung ialah pada saat pelaksanaan di masjid. pada saat rangakaian ini panitia akan mengundang seorang ustadz atau kiyai untuk berceramah memberikan tausyiah serta para pemuka agama dan tokoh masyarakat yang ada pada setiap lingkungan di Dasan Agung. Pada saat perayaan maulid di masjid, masyarakat menaikkan dulang sebanyak tiga kali untuk menjamu tamu undangan. Terdapat tiga jenis dulang yang ada yaitu dulang penyampah, dulang nasi, dan dulang penamat. Pada saat penaikan dulang terakhir dirangkaian dengan namatang (khataman Al Quran) dan ngurisang (Aqiqah). (3) Perayaan maulid di rumah-rumah masyarakat, mengundang kerabat, teman ataupun rekan untuk merayakan maulid di rumah juga menjadi salah satu tradisi perayaan maulid nabi di Dasan Agung. Perayaan maulid nabi di rumah masyarakat secara umum ialah undangan untuk memberikan jamuan dengan jajan tradisional ataupun nasi dan lauk-pauk. (4) Praje, dilakukan pada hari perayaan maulid yaitu setelah selesainya rangkaian acara di masjid. Dimulai pada malam hari setelah selesai melaksanakan ibadah sholat isya. Para tamu undangan akan berkumpul di rumah yang mengadakan praje, disana mereka akan dijamu dengan makanan dan minuman. Makanan yang disediakan ialah makanan seperti jajan tradisional ataupun nasi beserta lauk-pauk. Terdapat satu tradisi yang masih melekat pada perayaan praje ini yaitu sebelum dimulainya monggok-monggok, tamu undangan akan disajikan tuak (Tuak merupakan sejenis minuman keras khas Pulau Lombok yang terbuat dari air pohon nira yang kemudian difermentasi sehingga berubah warna, bau, serta rasanya dan mampu menciptakan 
efek halusinasi). Arak-arakan berkeliling memutari Jalan Gunung Pengsong kemudian mengelilingi Dasan Agung melalui Jalan Gunung Lawu kemudian menuju Jalan Langko kembali lagi menuju rumah melalui Jebak Beleq, selama berjalan mengelilingi rute tersebut arak-arakan akan memutar beberapa lagu diiringi tarian oleh barisan arak-arakan tersebut. Lagu-lagu yang diputar beragam, mulai dari lagu dangdut, pop Indonesia, india, hingga lagu-lagu barat. Ketika arak-arakan melewati masjid, barisan arak-arakan akan memberikan shalawat kepada masjid. Shalawat merupakan istilah yang digunakan ketika memberikan sumbangan umumnya berupa uang. (5) Pawai dan shalawatan, dua hari setelah dilaksanakannya perayaan praje, masyarakat Dasan Agung melakukan pawai selama tiga dengan tema yang berbeda-beda. Pada hari pertama pawai bertema bebas, masyarakat yang mengikuti pawai dibebaskan memilih tema kostum masing-masing. Pawai hari kedua ialah pawai sepeda, seluruh masyarakat Dasan Agung yang mempunyai sepeda keluar untuk meramaikan pawai dan menghias sepeda dengan berbagai tema dan hiasan. Dan pawai terakhir yaitu pawai takbiran. Pawai takbiran ialah pawai yang diikuti oleh hampir seluruh masyarakat Dasan Agung Gapuk. Dikatakan pawai takbiran ialah dikarenakan pawai puncak dimana masyarakat Dasan Agung gapuk dibebaskan dalam berkreasi menggunakan atribut apapun. Selama tiga hari pelaksanaan pawai tersebut, masyarakat Dasan Agung juga bershalawat untuk masjid dengan menyumbangkan uang semampu mereka.

Perayaan Maulid Nabi Muhammad SAW pada awalnya digunakan oleh para ulama untuk menyebarkan ajaran Islam kepada masyarakat, dengan mengadakan akulturasi kebudayaan yang kemudian menjadikan Maulid Nabi sebagai salah satu tradisi yang dimaknai sebagai hari peringatan kelahiran Nabi Muhammad SAW untuk meneladani kehidupan Nabi. Hingga kini perayaan Maulid Nabi bagi masyarakat Dasan Agung masih memiliki pemaknaan yang sama mengenai perayaan Maulid Nabi secara umum. Namun, pada beberapa rangkaian perayaan maulid nabi di Kelurahan Dasan Agung mengalami perubahan. Salah satu rangkaian perayaan maulid nabi Muhammad SAW yang cukup banyak mengalami perubahan ialah pada praje. Praje merupakan salah satu rangkaian perayaan maulid nabi Muhammad SAW di kelurahan Dasan Agung yang sudah ada sejak dahulu. Praje ialah rangkaian perayaan maulid nabi muhammad SAW di Kelurahan Dasan Agung yang dikhususkan untuk anak-anak yang telah dikhitan sebagai ucapan selamat dan syukur. Anak-anak yang telah dikhitan akan diponggok-ponggok menggunakan ornamen semacam singgasana berbentuk kuda. Terdapat perubahan pada bentuk ornamen praje saat ini dengan praje di atas tahun 1970, yaitu pada di atas tahun 70-an bentuk praje ialah ornamen masjid. Pada tahun 1972 ada seorang masyarakat Dasan Agung Lingkungan Gapuk Utara mengenalkan penggunaan praje menggunakan kuda. Lama-kelamaan masyarakat mulai mengganti kuda dengan kuda-kudaan sampai saat ini. Musik yang mengiringi praje juga mengalami 
perubahan diawal tahun 80 -an dari musik-musik religius menjadi musik dangdut, hingga sekarang menggunakan berbagai macam musik. Berikut beberapa rangkaian perayaan maulid nabi di kelurahan Dasan Agung yang mengalami perubahan makna dapat dilihat dalam uraian.

Masyarakat Dasan Agung, menyiapkan dan menyajikan dulang didasari oleh tindakan-tindakan tradisional atau sebagai sebuah tradisi yang ada pada masyarakat. Menyajikan dulang setiap perayaan maulid nabi telah mejadi kesadaran bersama bagi masyarakat Dasan Agung. Hal ini seperti temuan data bahwa setiap informan mengatakan bahwa menyajikan dulang telah dilakukan sejak dahulu. Adanya kesadaran bersama kemudian membentuk perilaku individu dengan pemahaman bahwa menyajikan dulang sesuatu hal yang diusahakan pada setiap perayaan maulid nabi. Memudarnya makna sebenarnya dari dulang tidak menandakan bahwa kini dulang tidak memiliki makna dikarenakan tidak adanya reduksi makna yang dilakukan oleh para ulama kepada masyarakat. Bagi masyarakat Dasan Agung kini makna dulang lebih mengarah kepada makna-makna sosial ekonomi.

Nilai-nilai matrealistis pada masyarakat Dasan Agung merupakan representasi kondisi masyarakat pada masa modernisasi. Dimana nilai-nilai luhur mulai terkikis dengan perkembangan zaman. Adanya perubahan yang terjadi pada praje. perkembangan teknologi yaitu adanya penggunaan salon atau sound system dengan taksiran harga mencapai dua juta untuk biaya sewa. Kemudian untuk mengangkut salon sepanjang parade arak-arakan dibutuhkan mobil pick up, sehingga total biaya yang dikeluarkan mengadakan praje saat ini dikatakan menghabiskan biaya yang cukup besar. Selain nilai matrealistis, konsumtif merupakan salah satu nilai yang dibawa oleh adanya modernisasi. Sifat konsumtif masyarakat Dasan Agung ditujukan dengan berhutang untuk mencukupi kebutuhan pelaksanaan praje. perubahan makna lainnya pada praje yaitu menjadikannya sebagai alasan untuk dimakluminya perilaku mabuk. Hal ini dikarenakan mereka yang akan memikul praje dianggap membutuhkan tenaga yang cukup karena akan berjalan mengarak praje. Kemudian diketahui bahwa tuak mampu memberikan sensasi santai. Namun pada realitasnya, masyarakat Dasan Agung yang ikut mabuk tidak hanya mereka yang akan memikul. Tidak sedikit pula masyarakat yang menyiapkan tuak bagi diri sendiri.

Tradisi menurut Shills adalah kumpulan benda material dan gagasan yang diberi makna khusus yang berasal dari masa lalu (Sztompka, 2014: 70). Begitu pula perayaan Maulid Nabi Muhammad SAW di Dasan Agung, masyarakat menganggapnya sebagai sesuatu yang diturunkan dari masa lalu dan memiliki makna-makna tertentu pada setiap komponennya. Masyarakat Dasan Agung memaknai perayaan Maulid Nabi sebagai peringatan hari kelahiran Nabi Muhammad SAW. Hal ini seperti yang diturunkan oleh para ulama kepada 
masyarakat. Dengan berbagai rangkaian perayaan Maulid Nabi yang masih terus dijalankan hingga saat ini.Masyarakat Dasan Agung memaknai perayaan Maulid Nabi sebagai peringatan kelahiran Nabi Muhammad SAW ditujukan oleh adanya rangkaian perayaan yang diisi dengan pengajian tentang meneladani kehidupan Nabi. Namun, hal ini tidak memastikan bahwa pada perayaan tidak terdapat perubahan makna. Kelurahan Dasan Agung terletak di tengah-tengah Kota Mataram. Posisinya yang berada di tengah kota menyebabkan proses-proses perubahan berjalan semakin cepat dan kompleks.

Perubahan sosial menurut Sztompka merupakan perubahan yang terjadi di dalam sistem sosial. Pada masyarakat Dasan Agung, perubahan pada sisetem sosial dan budaya ialah berubahnya makna Malid Nabi yakni sebagai acara makan-makan. Adanya perubahan tersebut kemudian menjadi sebuat kebiasaan masyarakat menyajikan makanan dan minuman pada saat perayaan Maulid Nabi. Dalam perubahan sosial dan budaya menurut Sztompka ialah adanya agen perubahan atau agent of change. Agen perubahan ialah para perencana dan pelaku perubahan, meski ada perubahan yang tidak direncanaan perubahan-perubahan yang terjadi pada tradisi perayaan Maulid Nabi. Perubahan terjadi dimulai dengan bertambahnya jumlah penduduk. Hal ini kemudian menyebabkan adanya budaya baru yang masuk pada suatu daerah. Nilai-nilai baru ini merupakan budaya yang akan berinteraksi dengan budaya lama, kemudian menyebabkan perubahan pada budaya lama. Masyarakat baru bisa kita katakan sebagai agen perubahan karena membawa budaya baru. Beberapa perubahan makna yang terjadi pada perayaan Maulid Nabi di Dasan Agung sangat erat kaitannya dengan perubahan sosial dan budaya yang terjadi pada masyarakat di sekitar Kota Mataram.

Kota Mataram sebagai Ibu Kota Provinsi Nusa Tenggara Barat, memiliki laju pertumbuhan budaya yang cukup signifikan. Kondisi masyarakat Kota Mataram yang heterogen, meningkatkan peluang terjadinya perubahan sosial budaya pada masyarakat Dasan Agung. Meskipun persebaran masyarakat pendatang tidak berpusat di Dasan Agung, namun interaksi tetap terjadi. Salah satu perubahan sosial dan budaya yang terjadi ialah perubahan makna perayaan Maulid Nabi sebagai penunjuk status sosial.

\section{Kesimpulan}

Berdasarkan hasil penelitian ini maka dapat ditarik kesimpulan yaitu. Proses perayaan Maulid Nabi di Kelurahan Dasan Agung terdiri dari persiapan perayaan dan pelaksanaan perayaan. Adapun proses persiapan perayaan yaitu (1) rapat persiapan panitia, (2) persiapan lomba, (3) menghias jalan dan masjid, (4) penampahan, (5) persiapan tamu undangan, dan (6) persiapan praje. Sedangkan proses pelaksanaan perayaan Maulid Nabi yaitu (1) pelaksanaan lomba, 
(2) pelaksanaan perayaan Maulid Nabi di masjid, (3) perayaan Maulid Nabi di rumah-rumah masyarakat, (4) praje, dan (5) pawai dan shalawatan. Perubahan makna perayaan Maulid Nabi Muhammad SAW bagi masyarakat Kelurahan Dasan Agung yaitu (1) perubahan makna yang ada pada dulang yaitu adanya anggapan bahwa rumah tangga yang mampu menaikkan dulang dalam jumlah besar memiliki kemampuan ekonomi yang tinggi, selain itu pembagian dulang pada saat perayaan Maulid Nabi di masjid menunjukkan status sosial orang tersebut. (2) perubahan makna dan pelaksanaan perayaan praje, pada perayaan praje masyarakat Dasan Agung memaknainya sebagai suatu perayaan yang ditujukan kepada anak-anak yang telah dikhitan serta sebagai simbol penujuk status sosial ekonomi masyarakat dikarenakan tingginya biaya pemenuhan perayaan praje serta semakin ramai yang menghadiri menunjukan status sosial yang tinggi. 


\section{Daftar Pustaka}

Afrizal. 2016. Metode Penelitian Kualitatif (Sebuah Upaya Mendukung Penggunaan Penelitian Kualitatif Dalam Disiplin Ilmu). Jakarta: Rajawali Pers

BPS Kecamatan Selaparang. 2018. Kecamatan Selaparang Dalam Angka Tahun 2018.(mataramkota.bps.go.id/kecamatan-selaparang-dalam-angka2018.html)

Damsar. 2015. Pengantar Teori Sosiologi. Jakarta: Kencana Prenadamedia Group Fuad, Ahmad. 2012. Foto Mabuk-Mabukan Mengiringi Maulid Di Kampungku. (http://papuqfotografi.blogspot.com/2012/02/foto-mabuk-mabukanmengiringi-maulid-di.html) (Diakses pada November 2017)

Handoko, Putut. Skripsi: Dampak Perkembangan Kampung Inggris Terhadap Perubahan Sosial Dan Budaya Masyarakat Desa Pelem Dan Desa Tulungrejo Pare-Kediri Jawa Timur. Surabaya: Universitas Dr. Soetomo Haryanto, Sindung. 2015. Sosiologi Agama: Dari Klasik Hingga Postmodern. Yogyakarta: Ar-Ruzz Media

Jabbar, M. Jalaluddin. Tradisi Maulid Nabi di Dasan Agung Mataram. (http://mjalaluddinjabbar.blogspot.com/2015/01/tradisi-maulid-nabi-didasan-agung.html) (Diakses pada November 2017)

Kamaluddin, Noor Aula. 2010. Skripsi: Peringatan Tradisi Maulid Nabi Muhammad SAW Serta Pembacaan Kitab Al-Barzanji Di Desa Pengandon Kecamatan Pegandon Kabupaten Kendal (Studi Kasus Komparatif Menurut Nahdlatul Ulama dan Muhammadiyah). Semarang: Institut Agama Islam Negeri Walisongo

Kuswana, Dadang. 2011. Metode Penelitian Sosial (Pengantar: Tajul Arifin). Bandung: CV. Pustaka Setia

Kuswarno, Engkus. 2013. Metodologi Penelitian Komunikasi: Fenomenologi: Konsepsi, Pedoman, dan Contoh Penelitian (Fenomenologi Pengemis Kota Bandung). Bandung: Widya Padjadjaran

Lubis, M. Ridwan. 2015. Sosiologi Agama (Memahami Perkembangan Agama Dalam Interaksi Sosial). Jakarta: Kencana

Maire, Z. 2015. Makna Peringatan Maulid Nabi Bagi Masyarakat Suku Sangihe (Studi di Desa Padengo Kecamatan Dengilo Kabupaten Pohuwato). Gorontalo: Universitas Negeri Gorontalo

Mansyur, Zaenuddin. 2005. Tradisi Maulid Nabi Dalam Masyarakat Sasak. Ulumuna Volume IX Edisi 15 No. 1.

Martono, Nanang. 2016. Sosiologi Perubahan Sosial (Perspektif Klasik, Modern, Posmodern, dan Poskolonial). Jakarta: Rajawali Pers 
Nurhayati, dan M. Turhan Yani. 2013. Transformasi Makna Tradisi UndhuhUndhuh Pada Era Globalisasi Mojowarni Jombang. Surabaya: Universitas Negeri Surabaya (UNESA)

Profil Dan Monografi Kelurahan Dasan Agung. (http://sipppid.mataramkota.go.id/file/profil-dan-monografi-kelurahan-dasanagung.pdf)

Renda, Trijuliani. 2012. Studi Kasus Tentang Sosial Di Sumba Timur Terhadap Persyaratan Gelar Kebangsawanan. Universitas Kristen Satya Wacana

Ritzer, George. 2014. Teori Sosiologi (Dari Sosiologi Klasik Sampai Perkembangan Terakhir Posmodern) (Alih bahasa: Saut Pasaribu, Sh. Widada, Eka Adi Nugraha). Yogyakarta: Pustaka Pelajar

Sanderson, Stephen K. 2011. Makrososiologi Sebuah Pendekatan Terhadap Realitas Sosial (Penerjemah: Farid Wajdi dan S. Menno)

Shofi, Muisy. 2015. Tinjauan Hukum Islam Terhadap Peringatan Mualid Nabi Muhammad Saw (Studi Komparasi Pendapat Nahdlatul Ulama Dan Muhammadiyah Di Desa Mayong Lor Kecamatan Mayong Kabupaten Jepara). Kudus: STAIN Kudus

Sukma, Selvina Muktining. 2015. Skripsi: Tradisi Grebeg Maulid Nabi Muhammad SAW Dalam Perspektif Pendidikan Islam Di Kota Madiun. Ponorogo: Sekolah Tinggi Ilmu Agama Islam (STAIN) Ponorogo.

Syarbaini, Syahril dan Fatkhuri. 2016. Teori Sosiologi Suatu Pengantar. Bogor: Ghalia Indonesia

Sztompka, Piötr. 2014. Sosiologi Perubahan Sosial (Penerjemah: Alimandan). Jakarta: Prenada

Zeitlin, Irving M. 1995. Memahami Kembali Sosiologi Kritik Terhadap Teori Sosiologi Kontemporer (Original edition: Rethinking Sociology a Critique of Contemporary Theory). Yogyakarta: Gadjah Mada University Press 